\title{
Conversion Characteristics of Some Major Cannabinoids from Hemp (Cannabis sativa L.) Raw Materials by New Rapid Simultaneous Analysis Method
}

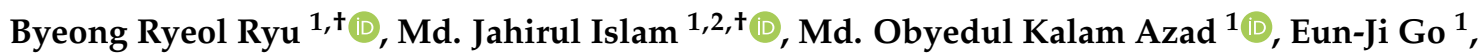 \\ Md. Hafizur Rahman ${ }^{1}$, Md. Soyel Rana ${ }^{1}$, Young-Seok Lim ${ }^{1, *}$ and Jung-Dae Lim ${ }^{1, * \mathbb{C}}$ \\ 1 Department of Bio-Health Convergence, Kangwon National University, Chuncheon 24341, Korea; \\ fbqudfuf0419@naver.com (B.R.R.); jahirulislam213@gmail.com (M.J.I.); azadokalam@gmail.com (M.O.K.A.); \\ a01040363654@daum.net (E.-J.G.); hafizknu94@gmail.com (M.H.R.); soyelrana98@gmail.com (M.S.R.) \\ 2 Physiology and Sugar Chemistry Division, Bangladesh Sugarcrop Research Institute, \\ Ishurdi, Pabna 6620, Bangladesh \\ * Correspondence: potatoschool@kangwon.ac.kr (Y.-S.L.); ijdae@kangwon.ac.kr (J.-D.L.); \\ Tel.: +82-33-250-6474 (Y.-S.L.); +82-33-540-3323 (J.-D.L.) \\ + These authors contribute equally.
}

\section{check for}

updates

Citation: Ryu, B.R.; Islam, M..J.; Azad, M..O.K.; Go, E.-J.; Rahman, M..H.; Rana, M..S.; Lim, Y.-S.; Lim, J.-D. Conversion Characteristics of Some Major Cannabinoids from Hemp (Cannabis sativa L.) Raw Materials by New Rapid Simultaneous Analysis Method. Molecules 2021, 26, 4113. https:// doi.org/10.3390/molecules26144113

Academic Editor: Andrea Mastinu

Received: 16 June 2021

Accepted: 4 July 2021

Published: 6 July 2021

Publisher's Note: MDPI stays neutral with regard to jurisdictional claims in published maps and institutional affiliations.

Copyright: (C) 2021 by the authors. Licensee MDPI, Basel, Switzerland. This article is an open access article distributed under the terms and conditions of the Creative Commons Attribution (CC BY) license (https:// creativecommons.org/licenses/by/ $4.0 /)$
Abstract: This study was carried out to develop a high-performance liquid chromatography method for short-time analysis of the main cannabinoids in the inflorescence of hemp (Cannabis sativa L.). We also performed decarboxylation of the raw material using our advanced analysis technique. In this study, the UV spectrum was considered to analyze each of the four common cannabinoids, solvents, and samples, where the uniform elution of acidic cannabinoids without peak tailing and acids was tested. Optimal results were obtained when readings were taken at a wavelength of $220 \mathrm{~nm}$ using water and methanol containing trifluoroacetic acid as mobile phases in a solvent gradient system. The established conditions were further validated by system suitability, linearity, precision, detection limit, and quantitation limit tests. The decarboxylation index $\left(\mathrm{DT}_{50}\right)$ confirmed that $\Delta 9$ THCA decarboxylated faster than CBDA, and both maintained a linear relationship with time and temperature. In addition, the loss of cannabidiol was better prevented during the decarboxylation process in the natural state than in the extracted state.

Keywords: cannabis; decarboxylation; cannabinoid; chromatography; cannabidiol

\section{Introduction}

Linnaeus classified hemp in Europe as a single species (Cannabis sativa L.) [1], and de Lamarck separately classified Indian varieties as Cannabis indica Lam. [2]. Janischevsky classified Russian-born hemp as Cannabis ruderalis Jansich. without any characteristics [3]. Even today, it remains controversial whether all cannabis should be viewed as a single species of C. sativa or as multiple species divided into C. sativa, C. indica, and C. ruderalis [4]. For convenience, it is indicated as 'Cannabis sativa L.'.

Hemp (Cannabis sativa L.) is an annual herb belonging to the Cannabaceae family, first recorded in China for the purpose of obtaining fiber [5]. Since then, it has been exploited for medical purposes for more than 10,000 years [6]. As many countries have approved hemp for medical applications, there has been a surge in the use of hemp drug therapy for pain relief [7]. Hemp contains more than 525 compounds and is known to express approximately 109 cannabinoids [8]. Cannabinoid refers to the C21 terpenophenol compound uniquely found in hemp [9]. Although expressed in small amounts in leaves, cannabinoid is mostly concentrated in the trichome part distributed in the bracts of the female flower of the plant. Its concentration is higher in the stalked-type trichome among the two types, 'sessile' and 'stalked' [10]. They are mostly present in the resin secreted from the trichomes of female plants, while male C. sativa have few glandular trichomes that can 
produce small amounts of psychoactive molecules [11]. The most abundant of these are the $\Delta$ 9-tetrahydrocannabinol ( $\triangle 9$-THC) and cannabidiol (CBD) families [12]. The compound $\triangle 9$-THC is a major psychotropic cannabinoid [13] known to induce transient psychotic and anxiety symptoms $[14,15]$. It was recently found to be effective in treating Alzheimer's disease and glaucoma [5]. CBD has an effect on anti-anxiety and anti-psychiatric diseases [16,17], and more than 1000 CBD-containing products are available in the market. It is thought to contain ingredients that can cure mental illness [18]. Each of these neutral cannabinoids is formed by non-enzymatic decarboxylation of acidic precursor cannabinoids called $\Delta$ 9-tetrahydrocannabinolic acid ( $\triangle 9$-THCA) and cannabidiolic acid (CBDA) (Figure 1) $[19,20]$, and heating temperature and time are known to significantly influence this decarboxylation process [21].

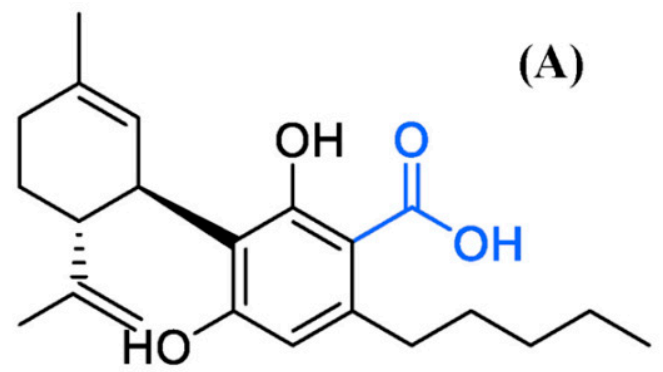

Figure 1. Carboxyl group of acid cannabinoids. tetrahydrocannabinolic acid. Carboxyl groups are removed by heat treatment and converted into neutral cannabinoids.

In this study, high-performance liquid chromatography (HPLC) was used to efficiently and accurately quantify four major cannabinoids ( $\triangle 9-\mathrm{THC}, \triangle 9-\mathrm{THCA}, \mathrm{CBD}$, and CBDA) that can be naturally and artificially converted. These compounds exhibit physiological activities. Simultaneous analysis conditions were developed, established, and employed to study the decarboxylation of cannabis inflorescence.

\section{Materials and Methods}

\subsection{Standard and Sample Preparation}

A sample of the inflorescence part of cannabis (Cannabis sativa L.) was received from the Korea Cannabis Genetic Resource Center (Chuncheon, Korea). An inflorescence sample of a plant grown for 105 days (50 days after flowering treatment) in a nutrient solution cultivation system after sowing was used. The standard products cannabidiol (CBD) and $\Delta$ 9-tetrahydrocannabinol ( $\triangle 9$-THC) were obtained from CAYMAN (Ann Arbor, MI, USA), the cannabidiolic acid (CBDA) standard product was from Cerilliant (Round Rock, TX, USA), and the $\triangle 9$-tetrahydrocannabinolic acid ( $\triangle 9$-THCA) standard product was manufactured by Sigma-Aldrich (St. Louis, MO, USA).

The inflorescence of freeze-dried hemp was pulverized using a chopper (YPT-1402, Young Polymer Tech Co., Incheon, Korea) certified by Korea Conformity Laboratories and filtered through a 12-mesh test sieve. The furnace particles were found to be homogeneous. In brief, $0.1 \mathrm{~g}$ of hemp sample was sonicated (JEIO TECH Co., Ltd., Daejeon, Korea) for 30 min with $30 \mathrm{~mL}$ extra pure grade $\mathrm{MeOH}$ (Daejung Chemicals and Metals Co., Ltd., Siheung, Korea) as an extraction solvent. After ultrasonic extraction at room temperature $\left(23 \pm 2{ }^{\circ} \mathrm{C}\right)$, the supernatant was sampled, filtered using a 0.45 -micrometer syringe filter (Advantec, Tokyo, Japan), and used for HPLC analysis.

All solutions except CBDA in stock state were precisely weighed and then diluted using $\mathrm{MeOH}$. The standard products and samples used in this study were received and tested with the approval of the Seoul Regional Food and Drug Administration (approval number: 1806). 


\subsubsection{HPLC Condition Setting}

HPLC was performed using a Shimadzu LC-20AT system with an SPD-20A detector (UV-Vis, Shimadzu Co., Kyoto, Japan) and a Zorbax SB-C18 column (Rapid Resolution, $4.6 \times 100 \mathrm{~mm}, 3.5 \mu \mathrm{m}$, Agilent Technologies, Inc., Santa Clara, CA, USA). HPLC-grade ultrapure water, methanol $\left(\mathrm{CH}_{3} \mathrm{OH}\right)$, and acetonitrile $\left(\mathrm{CH}_{3} \mathrm{CN}\right)$ were purchased from Mallinckrodt Baker (Phillipsburg, NJ, USA). The $\triangle 9$-THC, $\triangle 9$-THCA, CBD, and CBDA standards were mixed at a final concentration of $100 \mu \mathrm{g} / \mathrm{mL}$ and subjected to analysis.

To determine the absorption region of each component, the absorbance spectrum was measured in the UV region of 190-400 nm. The spectra of methanol and acetonitrile were also measured in the same region to avoid the cut-off section of the solvent.

We analyzed the mixture of ultrapure water and selected organic solvents at concentrations of $60 \%, 70 \%, 80 \%$, and $90 \%$ to improve kurtosis and skewness by adjusting pKa. Formic acid (FA, Merck, Darmstadt, Germany), trifluoroacetic acid (TFA, Sigma-Aldrich Co., St. Louis, MO, USA), and phosphoric acid (PA, Junsei Chemical Co., Ltd., Tokyo, Japan) were added at concentrations of $0.01 \%, 0.05 \%$, and $0.10 \%$, respectively, to explore optimal mobile conditions.

\subsubsection{Validation for Establishing Analysis Conditions}

To determine the suitability of the developed analysis conditions, tests of the system suitability, specificity, linearity, range, accuracy, precision, detection limit, and quantitation limit were conducted with reference to the ICH guideline Q2 (R1) [22]. The United States Pharmacopeia (USP) was used to determine the suitability of the system.

\subsection{Investigation of the Correlation between Hemp Inflorescence and Decarboxylation}

Samples ground in the same manner as previously described were placed in a preheated, closed, dry oven (Sungchan Science Co., Pocheon, Korea) and sampled at 5-min intervals for $60 \mathrm{~min}$. The temperature conditions were $90,105,120$, and $135^{\circ} \mathrm{C}$.

To compare the decarboxylation of the extract and the natural product, two different types of cannabis extract were additionally prepared, extracted by applying the above extraction method, and concentrated at $30^{\circ} \mathrm{C}$ using a rotary evaporator (Tokyo Rikakikai). The moisture was removed using a freeze-dryer (FD8512, IlShinBioBase Co., Ltd., Dongducheon, Korea). After decarboxylation at $135^{\circ} \mathrm{C}$ for $30 \mathrm{~min}$ in the absence of any solvent, the product was recovered with $\mathrm{MeOH}$ and used for analysis.

\section{Results}

\subsection{HPLC Condition Setting}

The absorbance spectrum of the standard solution in the UV region was measured and compared with the mAU value. As a result, $\triangle 9$-THC, $\triangle 9$-THCA, CBD, and CBDA had their maximum absorbance at 210.50, 221.24, 209.09, and $221.51 \mathrm{~nm}$, respectively (Figure 2). Cannabinoids in the form of acidic precursors had relatively low absorbance in the UV region. The cut-off section of the mobile phase allowed us to judge whether it was easy to analyze at the selected wavelength (Figure 3). Acetonitrile and HPLC water showed an absorbance lower than or similar to that of the baseline at $220 \mathrm{~nm}$, and methanol had a slightly higher absorbance than that of the baseline. This observation was consistent with that reported by Welch et al. [23]. We chose $220 \mathrm{~nm}$ as the optimal wavelength and acetonitrile as the organic mobile phase to facilitate sensitive peak detection, solvent absorption, and simultaneous analysis.

Peak tailing tends to lower the peak height and increase the limit of detection (LOD) and limit of quantitation (LOQ). As the area of the peak cannot be accurately determined, the reliability of quantification is automatically reduced. In the case of $\triangle 9$-THCA, which was eluted at the end, tailing occurred due to diffusion in the column and unstable kurtosis; therefore, the flow rate was set to $1.5 \mathrm{~mL} / \mathrm{min}$.

We used water as the polar solvent and $60 \%, 70 \%, 80 \%$, and $90 \%$ as ACN. Separation was performed for $40 \mathrm{~min}$ using the isocratic method. Based on the last eluted THCA, 60\% 
of cases were not detected within $40 \mathrm{~min}$; at 70\% RT, 10.314 ( $\triangle 9$-THCA); 80\% RT, 5.922 ( $\triangle 9$-THCA); and 90\% RT, 3.059 ( $\triangle 9$-THCA). The peaks of all spiked standards except for those with $90 \% \mathrm{ACN}$ were isolated; however, CBDA peak splitting occurred in the presence of $80 \%$ or higher ACN. Thus, $70 \% \mathrm{ACN}$ was selected as the optimal solvent.

The organic acids $0.05 \%$ TFA, $0.10 \%$ PA, and $0.10 \%$ FA were used under gradient conditions, and the gradient eluent set to simulation was used as the elution method to increase the elution rate (initiation, $70 \% \mathrm{ACN} ; 2 \mathrm{~min}, 70 \% \mathrm{ACN} ; 8 \mathrm{~min}, 85 \% \mathrm{ACN} ; 9 \mathrm{~min}$, $70 \%$ ACN; $12 \mathrm{~min}, 70 \% \mathrm{ACN}$ ). FA and TFA showed a raised baseline (Figure 4). However, TFA was selected as the optimal organic acid because PA is not very compatible with mass spectrometry (MS), such as liquid-chromatography-mass-spectrometry (LC-MS) or liquid chromatography quadrupole time-of-flight (LC-Q-ToF).

The chromatography conditions were as follows: mobile phase A was water containing $0.05 \%$ TFA and mobile phase $\mathrm{B}$ was ACN containing $0.05 \%$ TFA. The gradient conditions were as follows: $70 \%$ B initially, $70 \%$ B for $2 \mathrm{~min}, 85 \%$ B for $8 \mathrm{~min}, 70 \%$ B for $9 \mathrm{~min}$, and $70 \%$ B for $12 \mathrm{~min}$. All four cannabinoids were measured at $220 \mathrm{~nm}$ using a UV-Vis detector. The flow rate was $1.5 \mathrm{~mL} / \mathrm{min}$. The injection volume was $10 \mu \mathrm{L}$, and the column oven temperature was set to $35^{\circ} \mathrm{C}$ to prevent the destruction of acid-type cannabinoids and to reduce the retention time.
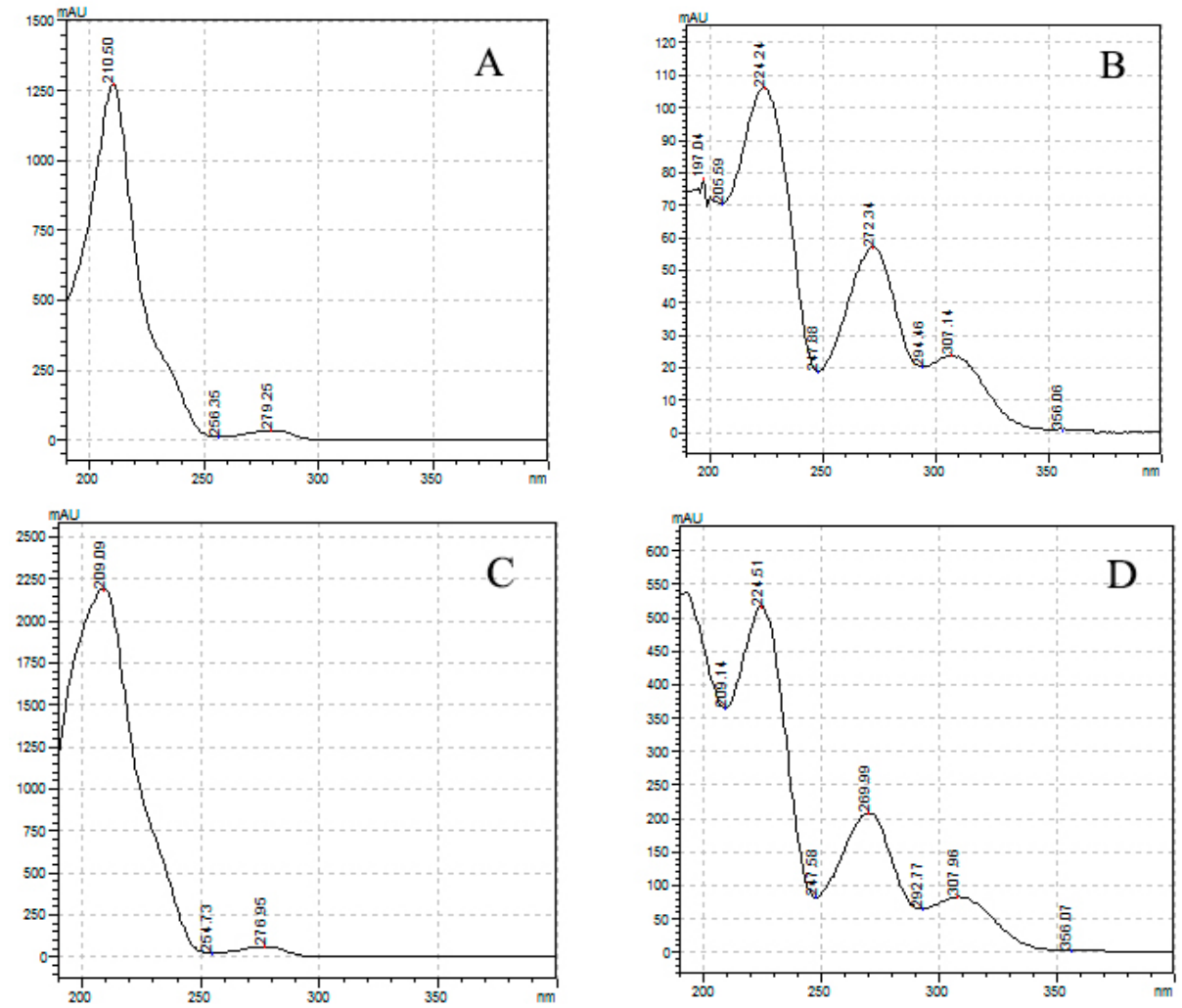

Figure 2. UV (ultraviolet) spectrum of four main cannabinoids. (A) $\Delta 9$-tetrahydrocannabinol, (B) $\Delta 9$ tetrahydrocannabinolic acid, (C) cannabidiol, and (D) cannabidiolic acid. Analysis was carried out from $190 \mathrm{~nm}$, the lowest detection wavelength of the instrument. 

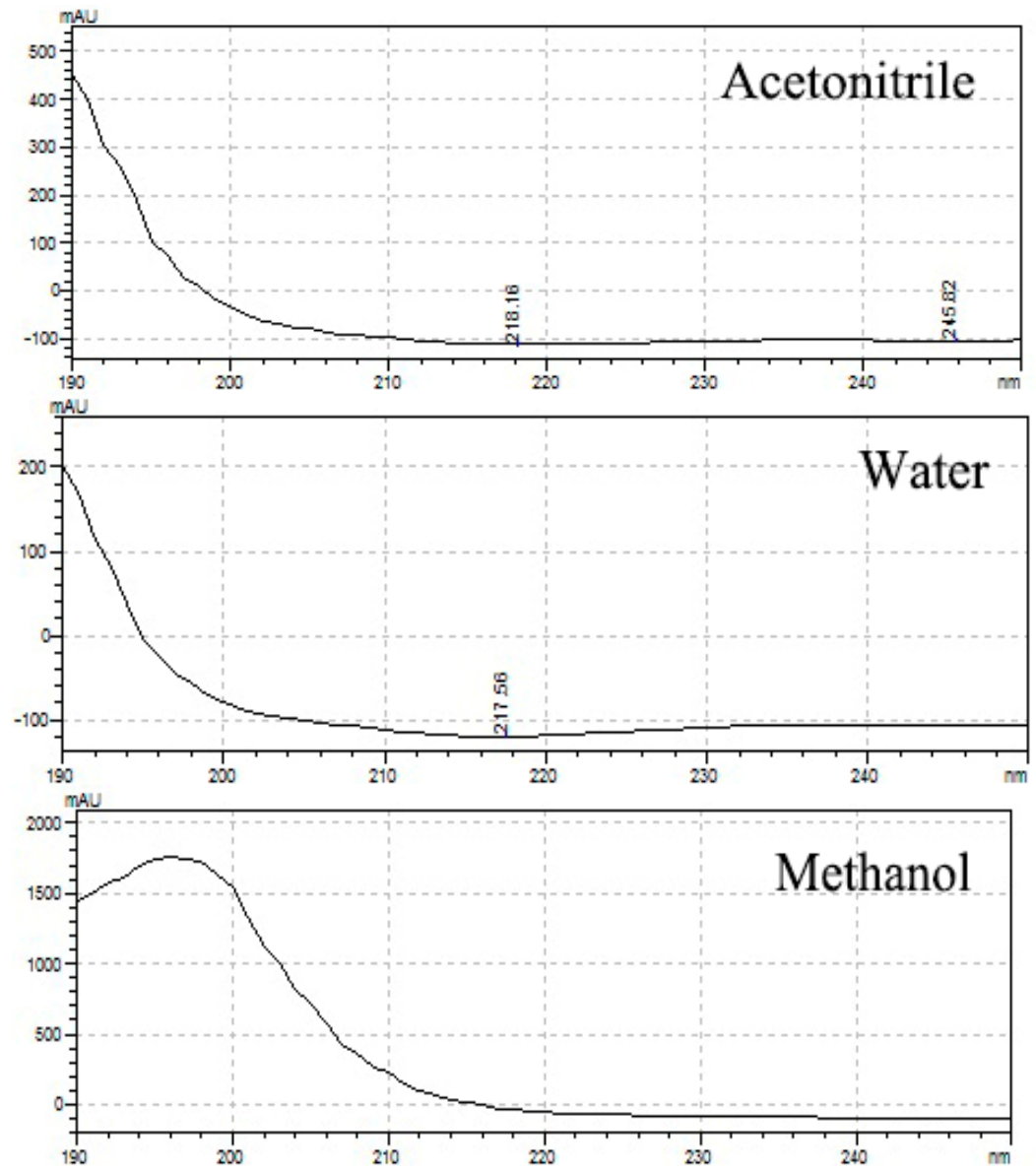

Figure 3. Absorbance spectrum of HPLC mobile phase; acetonitrile, methanol, and HPLC water. Analysis was carried out from $190 \mathrm{~nm}$, the lowest detection wavelength of the instrument.

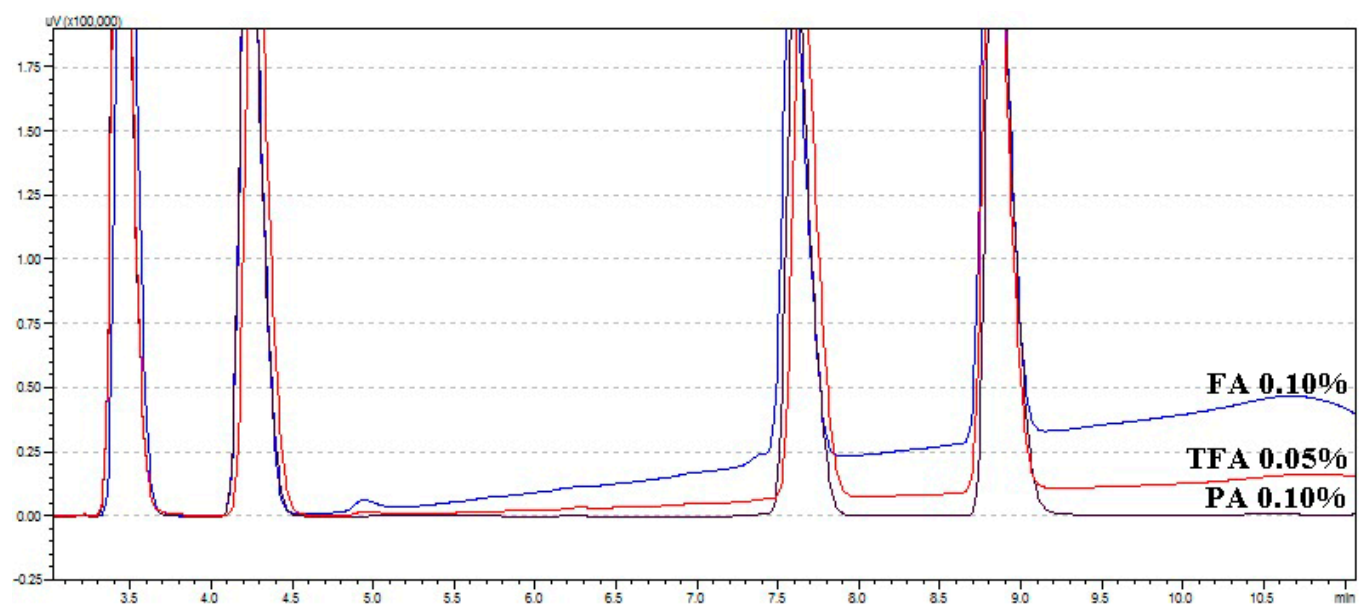

Figure 4. Analysis of four standards $(100 \mu \mathrm{g} / \mathrm{mL})$ under gradient conditions including acid. Blue line, $0.10 \%$ formic acid (FA); red line, $0.05 \%$ trifluoroacetic acid (TFA); black line, $0.10 \%$ phosphoric acid (PA).

\subsection{Validation}

\subsubsection{System Suitability Test}

A standard stock solution was prepared, and four types of standard products were mixed and measured nine times at the same concentration. The retention time did not exceed $2.00 \%$ of the relative standard deviation in $\%(\mathrm{RSD} \%)$ values for all four cannabinoids, 
and the peak area was less than $1.00 \%$. The tailing factor was less than 2.0, and all theoretical plates had values of 1000 or more, thus meeting all USP standards. For resolution, CBDA, CBD, $\triangle 9$-THC, and $\triangle 9$-THCA with similar retention times were compared, thus showing excellent resolution (Table 1).

Table 1. Results of system suitability test $(n=9)$.

\begin{tabular}{|c|c|c|c|c|c|c|c|c|c|c|c|c|}
\hline & Cannabinoid & 1 & 2 & 3 & 4 & 5 & 6 & 7 & 8 & 9 & Aver. & RSD $\%$ \\
\hline \multirow{2}{*}{ Resolution } & $\begin{array}{c}\Delta 9-\mathrm{THCA} \\
\Delta 9-\mathrm{THC}\end{array}$ & 5.995 & 5.971 & 5.99 & 5.98 & 5.997 & 5.984 & 5.987 & 5.987 & 5.983 & 5.986 & \multirow{2}{*}{ - } \\
\hline & $\begin{array}{l}\text { CBD } \\
\text { CBDA }\end{array}$ & 4.042 & 4.043 & 4.029 & 4.028 & 4.024 & 4.04 & 4.041 & 4.061 & 4.034 & 4.038 & \\
\hline \multirow{4}{*}{$\begin{array}{l}\text { T. plate } \\
\text { number }\end{array}$} & $\triangle 9-\mathrm{THCA}$ & 25,869 & 25,501 & 25,438 & 25,804 & 25,857 & 25,816 & 25,420 & 25,769 & 25,804 & 25,698 & \multirow{4}{*}{-} \\
\hline & $\Delta 9-\mathrm{THC}$ & 18,632 & 18,672 & 18,611 & 18,596 & 18,642 & 18,606 & 18,601 & 18,571 & 18,591 & 18,614 & \\
\hline & CBD & 6914 & 6947 & 6806 & 6921 & 6838 & 6917 & 6911 & 6908 & 6911 & 6897 & \\
\hline & CBDA & 5980 & 5893 & 5987 & 5987 & 5900 & 5983 & 5980 & 5973 & 5980 & 5963 & \\
\hline \multirow{4}{*}{$\begin{array}{l}\text { Tailing } \\
\text { factor }\end{array}$} & $\triangle 9$-THCA & 1.4 & 1.4 & 1.39 & 1.4 & 1.38 & 1.39 & 1.39 & 1.39 & 1.39 & 1.39 & \multirow{4}{*}{-} \\
\hline & $\Delta 9-\mathrm{THC}$ & 1.38 & 1.38 & 1.38 & 1.38 & 1.37 & 1.37 & 1.37 & 1.37 & 1.38 & 1.38 & \\
\hline & CBD & 1.34 & 1.34 & 1.34 & 1.35 & 1.35 & 1.35 & 1.34 & 1.32 & 1.35 & 1.34 & \\
\hline & CBDA & 1.4 & 1.4 & 1.41 & 1.4 & 1.41 & 1.39 & 1.39 & 1.39 & 1.4 & 1.4 & \\
\hline \multirow{4}{*}{ Peak area } & $\Delta 9-\mathrm{THCA}$ & $1,500,678$ & $1,497,089$ & $1,494,576$ & $1,489,975$ & $1,498,975$ & $1,509,757$ & $1,509,785$ & $1,498,546$ & $1,509,901$ & $1,501,031$ & 0.484 \\
\hline & $\triangle 9-\mathrm{THC}$ & $1,245,445$ & $1,253,876$ & $1,247,264$ & $1,247,879$ & $1,249,487$ & $1,254,579$ & $1,250,047$ & $1,251,057$ & $1,226,789$ & $1,247,380$ & 0.663 \\
\hline & CBD & 477,667 & 477,348 & 473,487 & 476,402 & 477,259 & 472,008 & 476,834 & 472,695 & 479,546 & 475,916 & 0.539 \\
\hline & CBDA & $1,775,767$ & $1,779,756$ & $1,766,487$ & $1,769,487$ & $1,767,534$ & $1,776,789$ & $1,779,785$ & $1,773,246$ & $1,775,875$ & $1,773,858$ & 0.282 \\
\hline \multirow{4}{*}{$\begin{array}{l}\text { Retention } \\
\text { time }\end{array}$} & $\Delta 9$-THCA & 8.815 & 8.82 & 8.809 & 8.804 & 8.813 & 8.806 & 8.806 & 8.798 & 8.804 & 8.808 & 0.076 \\
\hline & $\triangle 9-\mathrm{THC}$ & 7.423 & 7.431 & 7.419 & 7.416 & 7.425 & 7.418 & 7.417 & 7.411 & 7.415 & 7.419 & 0.081 \\
\hline & CBD & 4.204 & 4.214 & 4.206 & 4.206 & 4.216 & 4.205 & 4.203 & 4.202 & 4.203 & 4.207 & 0.119 \\
\hline & CBDA & 3.384 & 3.392 & 3.386 & 3.386 & 3.394 & 3.385 & 3.384 & 3.382 & 3.384 & 3.386 & 0.118 \\
\hline
\end{tabular}

\subsubsection{Linearity}

To test linearity, standard products were prepared at concentrations of 20,40, 80, 160,320 , and $640 \mu \mathrm{g} / \mathrm{mL}$, and calibration curves were measured using newly developed analysis methods. The coefficient of determination $\left(R^{2}\right)$ of the evaluated calibration curve was as follows: CBDA, $\mathrm{R}^{2}=0.9916 ; \mathrm{CBD}, \mathrm{R}^{2}=0.9993 ; \Delta 9-\mathrm{THC}, \mathrm{R}^{2}=0.9944$; and $\triangle 9$-THCA, $\mathrm{R}^{2}=0.9994$. Thus, we observed excellent linearity above $\mathrm{R}^{2} \geq 0.9900$. However, in the case of CBDA and $\triangle 9-T H C$, the $\mathrm{R}^{2}$ values were 0.9999 and 0.9986 , respectively, when the maximum concentration of $640 \mu \mathrm{g} / \mathrm{mL}$ was removed. This observation was associated with the high concentration, which violates the Beer-Lambert law because of the characteristics of the calibration curve. In the case of quantitative analysis, CBDA and $\triangle 9-T H C$ should be analyzed by excluding $640 \mu \mathrm{g} / \mathrm{mL}$ (Figure 5).

\subsubsection{Precision}

To establish the precision of the analysis method, intra-day and inter-day analyses were performed over 2 days with five repetitions. The intra-day RSD $\%$ was $0.053-0.157$ for CBDA, $0.641-1.203$ for CBD, 0.689-1.329 for $\triangle 9$-THC, and 0.424-0.486 for $\triangle 9$-THCA. The inter-day RSD $\%$ for CBDA, CBD, $\triangle 9$-THC, and $\triangle 9$-THCA was $0.181,1.944,1.018$, and 0.590 , respectively.

\subsubsection{LOD and LOQ}

The LOD and LOQ were measured using the standard products at low concentrations of 10.0, 1.0, 0.5, and $0.1 \mu \mathrm{g} / \mathrm{mL}$. The qualitative limit was judged to be effective when the signal/noise (S/N) value was at least 3.000, and it was $<0.1 \mu \mathrm{g} / \mathrm{mL}$ for CBDA (S/N: 10.181), $<0.5 \mu \mathrm{g} / \mathrm{mL}$ for CBD (S/N: 6.985), $<0.5 \mu \mathrm{g} / \mathrm{mL}$ for $\Delta 9-\mathrm{THC}$ (S/N: 16.654 ), and $<0.5 \mu \mathrm{g} / \mathrm{mL}$ for $\triangle 9$-THCA (S/N: 28.372). The LOQ was judged to be effective when the $\mathrm{S} / \mathrm{N}$ value was at least 10.000, and it was found to be $<0.1 \mu \mathrm{g} / \mathrm{mL}$ for CBDA (S/N: 10.181), $<1.0 \mu \mathrm{g} / \mathrm{mL}$ for CBD (S/N: 13.272), $<0.5 \mu \mathrm{g} / \mathrm{mL}$ for $\Delta 9$-THC (S/N: 16.654 ), and $<0.5 \mu \mathrm{g} / \mathrm{mL}$ for $\Delta 9$-THCA $(\mathrm{S} / \mathrm{N}$ : 28.372). All cannabinoids were detected at or below $0.5 \mu \mathrm{g} / \mathrm{mL}$, and quantification was possible at or below $1.0 \mu \mathrm{g} / \mathrm{mL}$. 


\subsection{Evaluation of Industrial Decarboxylation Efficiency of Hemp Inflorescence}

Heat is a major factor in cannabis decarboxylation [24]. Therefore, we analyzed the decarboxylation graph according to temperature and heating time using the newly established simultaneous analysis conditions. Figure 6 shows the decrease in the acidic form of cannabinoid and the increase in its neutral form. This decarboxylation reaction was accelerated as the temperature and time increased and showed a pattern similar to that reported in previous studies [21,25].
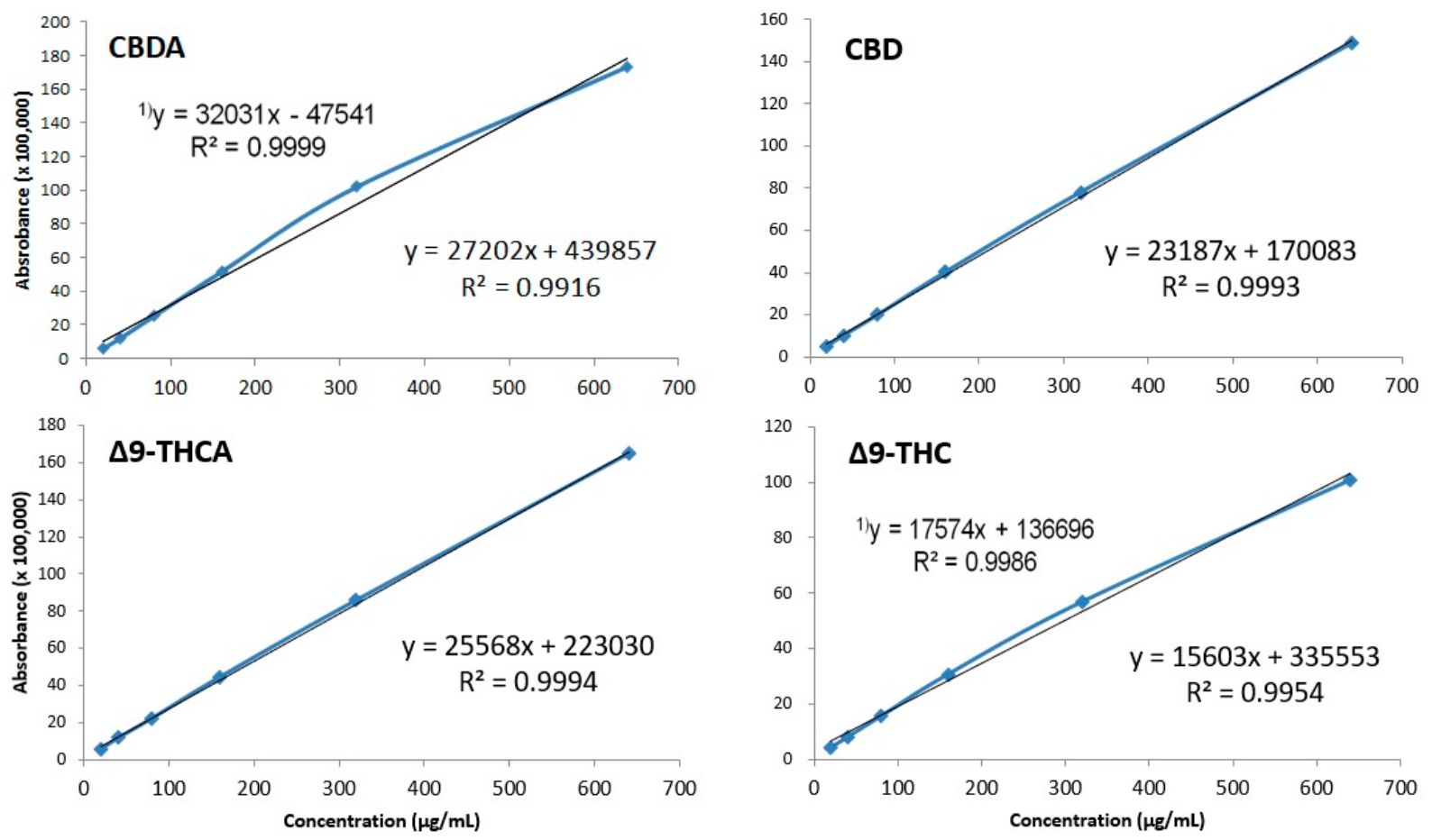

Figure 5. Calibration curves of four cannabinoids shown through the method of least squares. Regression equation and correlation coefficient with $640 \mu \mathrm{g} / \mathrm{mL}$ deleted. CBDA and $\Delta 9-\mathrm{THC}$ at $640 \mu \mathrm{g} / \mathrm{mL}$ were excluded from the quantification due to the violation of the Beer-Lambert law.

Hemp without additional processing also undergoes decarboxylation in its natural state owing to the effects of environmental factors such as light, and also generates neutral cannabinoids [26]. We selected the $\mathrm{DT}_{50}$ parameter (when acid cannabinoids are reduced by half; half-life) to accurately evaluate the rate of decarboxylation by removing the cannabinoid factors that are oxidized during heating and naturally generated neutral cannabinoids. $\mathrm{DT}_{50}$ was not achieved at $90^{\circ} \mathrm{C}$ in either CBDA or $\triangle 9$-THCA after $60 \mathrm{~min}$. The $\mathrm{DT}_{50}$ was 44.4 for $\mathrm{CBDA}$ and 39.1 for $\triangle 9$-THCA at $105^{\circ} \mathrm{C}, 32.6$ for CBDA and 27.3 for $\triangle 9$-THCA at $120{ }^{\circ} \mathrm{C}$, and 25.8 for CBDA and 21.1 for $\triangle 9$-THCA at $135{ }^{\circ} \mathrm{C}$. As for decarboxylation, $\triangle 9$-THCA had a $\mathrm{DT}_{50}$ value of approximately $5.1 \pm 0.3$ at the same temperature as CBDA, suggesting that $\triangle 9$-THCA decarboxylated faster than CBDA did under the same conditions (Figure 7).

The purpose of this study was to compare the loss of neutral cannabinoids from natural products and extracts in response to heating at a maximum temperature of $135^{\circ} \mathrm{C}$ for 30 min using randomly selected CW21-13 and RDA-35 varieties. The $\mathrm{DT}_{50}$ values of the acidic cannabinoids were not noticeably different for both extracts and natural products. Thus, neither the extract nor the natural product had any effect on the decarboxylation rate. 


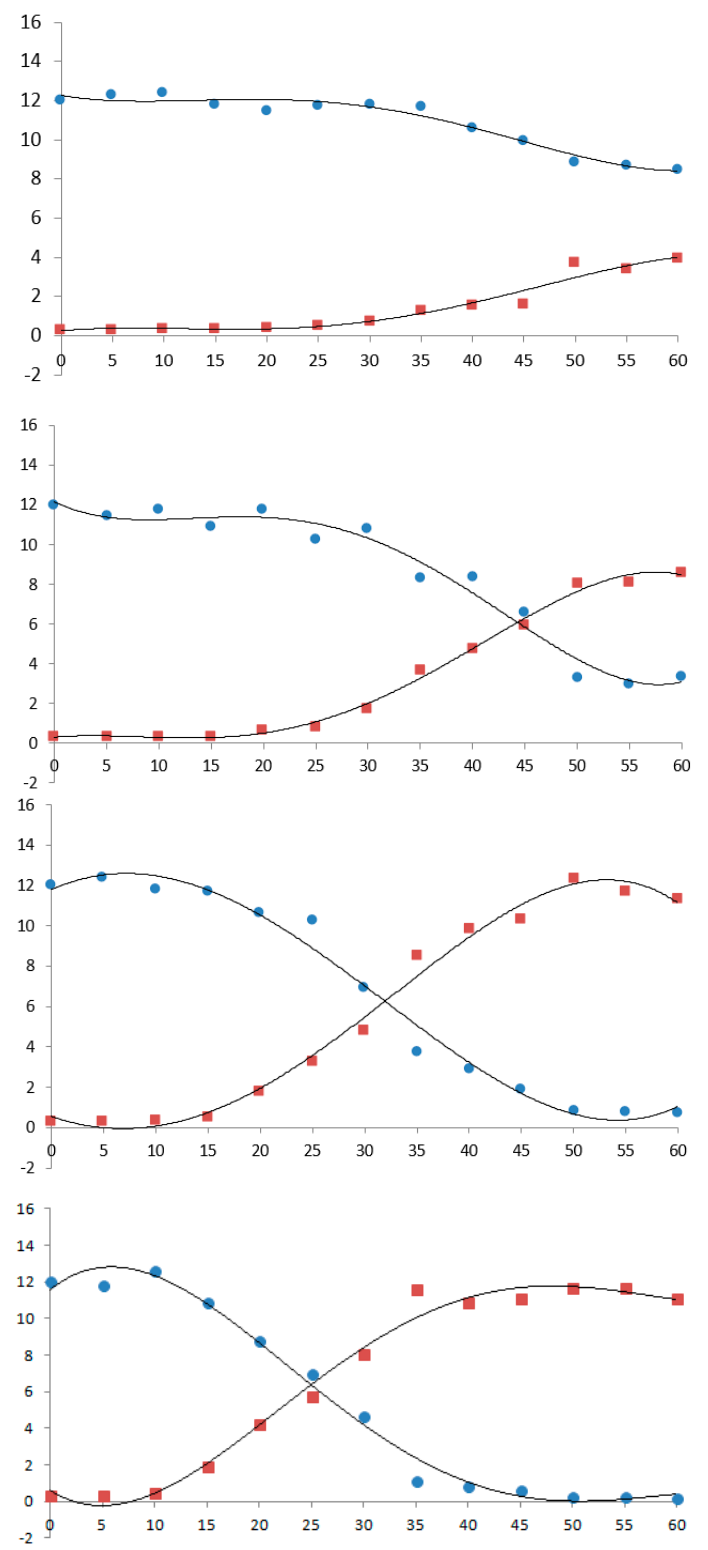

(A)

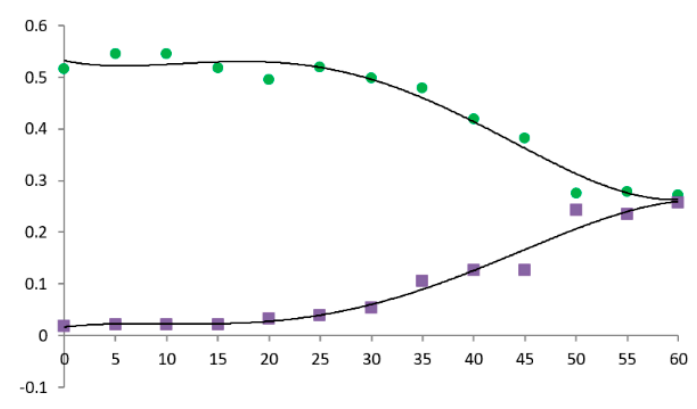

(B)

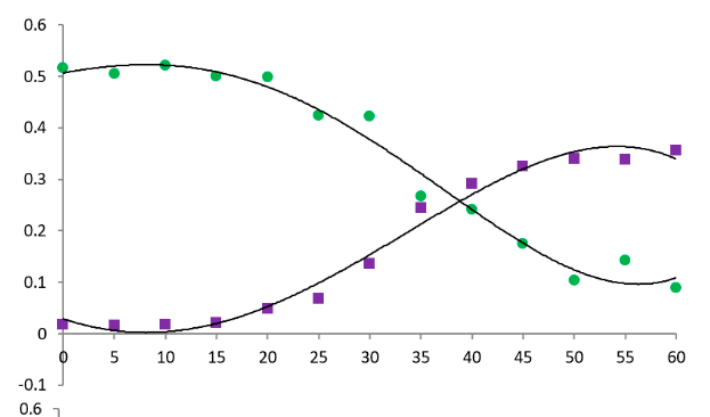

(C)

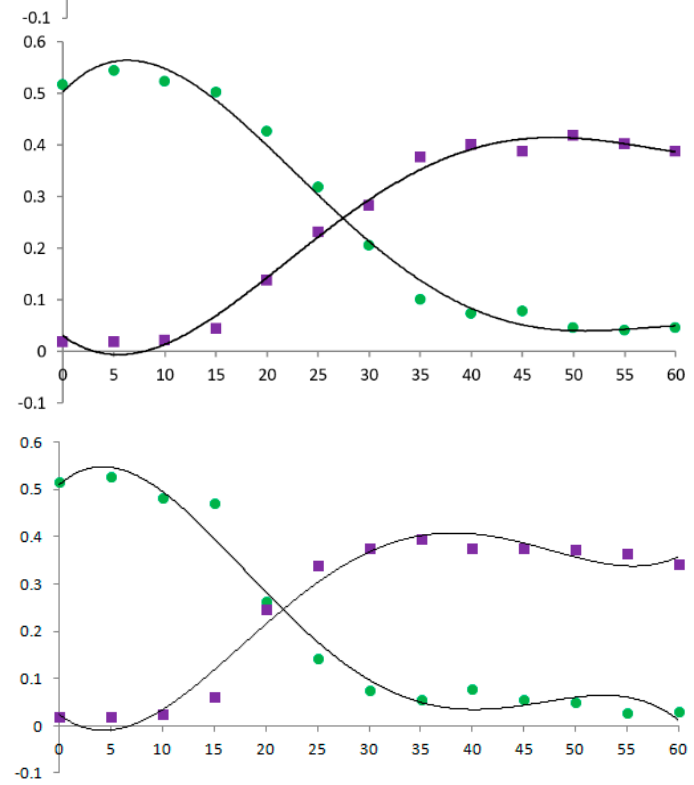

Figure 6. Decarboxylation curve of hemp flower powder with changes in temperature and time. (A) $90{ }^{\circ} \mathrm{C}$; (B) $105^{\circ} \mathrm{C}$; (C) $120^{\circ} \mathrm{C}$; (D) $135^{\circ} \mathrm{C}$. X-axis, time (min); Y-axis, concentration $(\mu \mathrm{g} / \mathrm{mL}, \times 10,000)$. Blue dots, CBDA; red dots, CBD; green dots, $\triangle 9$-THCA; purple dots, $\triangle 9$-THC.

Upon incubation for $30 \mathrm{~min}$ at $135{ }^{\circ} \mathrm{C}$, the yield of neutral cannabinoids increased in CW21-13. The CBD content of the raw material and extract was 33,786 and 10,046 $\mu \mathrm{g} / \mathrm{mL}$ (about 3.4 times), respectively, and the $\triangle 9-\mathrm{THC}$ content was 956 and $235 \mu \mathrm{g} / \mathrm{mL}$ (about 4.0 times), respectively. In the case of RDA-35, the CBD and $\triangle 9-T H C$ contents of the raw material were 19,756 and $792 \mu \mathrm{g} / \mathrm{mL}$, respectively, and those of the extract were $6306 \mu \mathrm{g} / \mathrm{mL}$ (about 3.1 times) and $155 \mu \mathrm{g} / \mathrm{mL}$ (about 5.1 times), respectively. Thermal destruction of neutral cannabinoids in the raw material was significantly lower in both varieties (Figure 8). Even during visual evaluation, the neutral cannabinoid levels increased over time in the extract and decreased in the second half. On the other hand, the natural product had a pattern of increase or did not continue to decrease even at $30 \mathrm{~min}$, the end-point of the experiment. 


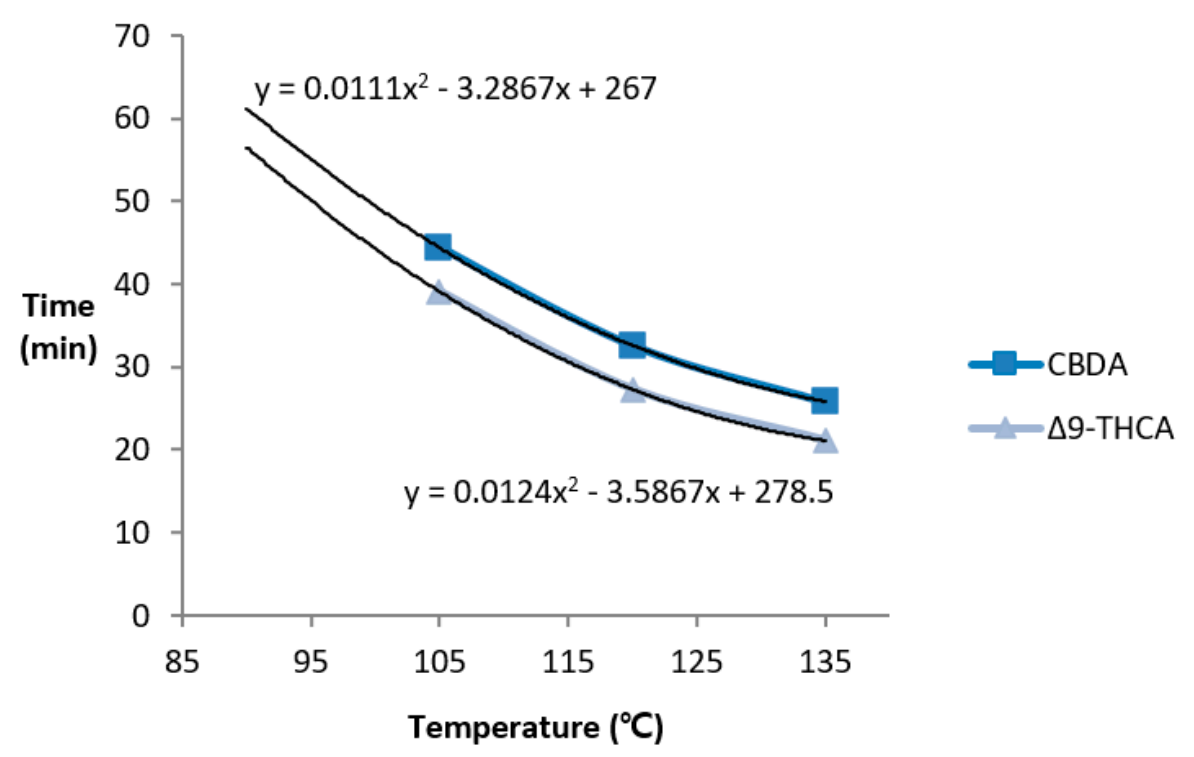

Figure 7. Time for 50\% decarboxylation ( $\mathrm{DT}_{50}$; when acidic cannabinoids are reduced to half) depending on the temperature. $\triangle 9$-THCA had a smaller $\mathrm{DT}_{50}$ value than CBDA did; decarboxylation occurred faster for THCA.

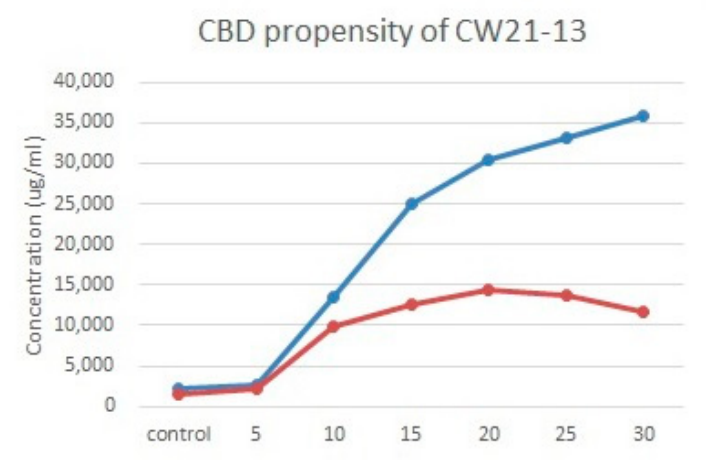

$\Delta^{9}$-THC propensity of CW21-13

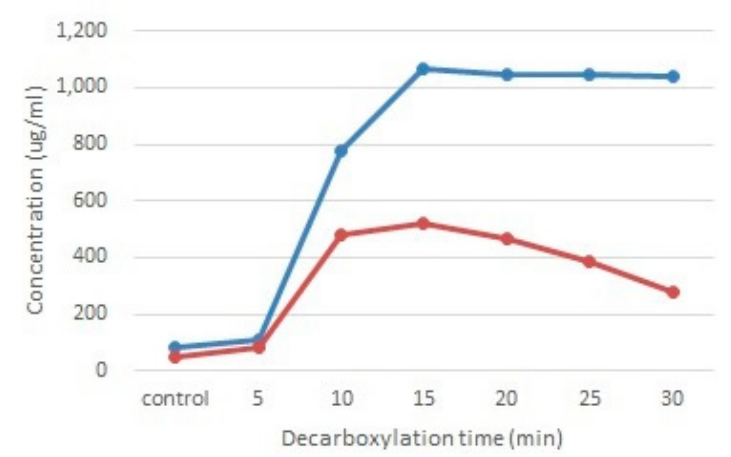

CBD propensity of RDA-35

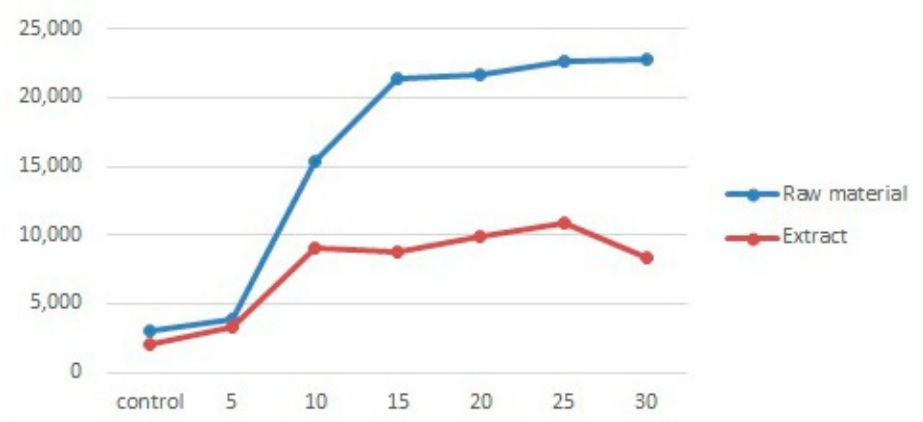

$\Delta^{9}$-THC propensity of RDA-35

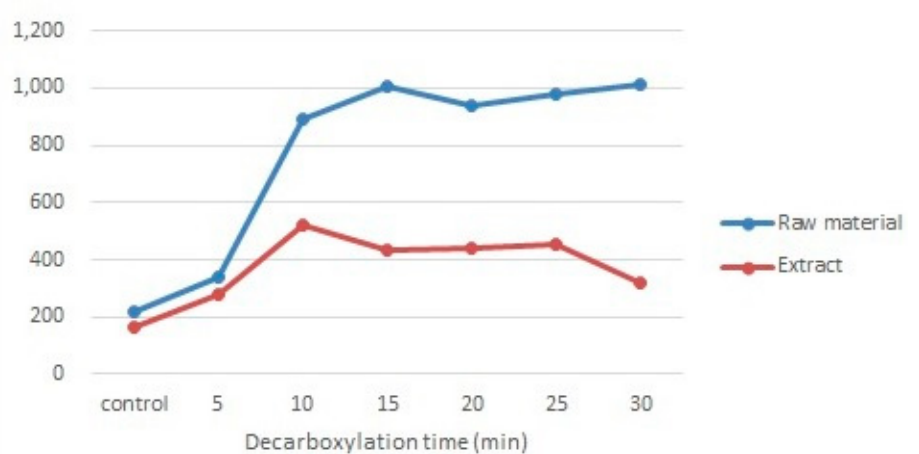

Figure 8. Loss of THC and CBD in different varieties at $135^{\circ} \mathrm{C}$ for $30 \mathrm{~min}$. Blue line, yield of raw material; red line, yield of extract. Samples were obtained every $5 \mathrm{~min}$ and analyzed, and all experiments were carried out simultaneously under the same conditions.

\section{Conclusions}

We have successfully developed a fast and reliable analytical method using the widely employed HPLC-UV/Vis system. The validation tests demonstrated the high suitability of the method. The decarboxylation process of hemp was analyzed using this chromatographic method, which successfully isolated four major cannabinoids within $10 \mathrm{~min}$. The 
overall decarboxylation rate may vary depending on factors such as the volume of the reactor due to the nature of the closed oven [27]. However, $\triangle 9$-THCA occurred more rapidly at a lower temperature than CBD did in natural products under the same conditions. The thermal destruction of cannabinoids occurred more in extracts than in natural products. The results of this study are of great value. This method allows for quick quantification and selection of the main cannabinoids in hemp breeding for industrial applications. In addition, it provides justification about the various processes that occur during the decarboxylation of hemp in its natural state.

Author Contributions: B.R.R. and M.J.I. conceived and designed the experiments, carried out all the experimental works, collected and analyzed the data, and drafted the final manuscript. M.O.K.A., E.-J.G., M.H.R. and M.S.R. improved the manuscript. Y.-S.L. and J.-D.L. validated all the protocols and supervised the study. All authors have read and agreed to the published version of the manuscript.

Funding: This research did not receive any specific grant.

Institutional Review Board Statement: Not applicable.

Informed Consent Statement: The standard products and samples used in this study were received and tested with the approval of the Seoul Regional Food and Drug Administration (approval number: 1806).

Data Availability Statement: Not applicable.

Acknowledgments: This research was supported by the Ministry of Science and ICT (MSIT, Korea), (support program: 2021-DD-UP-0379) and the BK21 FOUR program of the National Research Foundation (NRF, Korea). The authors also express their gratitude and pro-found appreciation to the CBF (Chuncheon Bioindustry Foundation, Korea) for the supporting in breeding program.

Conflicts of Interest: The authors declare no conflict of interest.

Sample Availability: Samples of the compounds are not available from the authors.

\section{References}

1. Linnaeus, C. Species Plantarum; Impensis Laurentii Salvii; Holmiae: Stockholm, Sweden, 1753.

2. de Lamarck, J.d.M. Encyclopedie Methodique. Botanique; Paris, Liege: Panckoucke, Plomteux, 1786.

3. Small, E. American law and the species problem in Cannabis: Science and semantics. Bull. Narc. 1975, 27, 1-20. [PubMed]

4. Hartsel, J.A.; Eades, J.; Makriyannis, A. Cannabis sativa and hemp. In Nutraceuticals: Efficacy, Safety and Toxicity, 1st ed.; Gupta, R.C., Ed.; Elsevier Inc.: San Diego, CA, USA, 2016; pp. 735-754; ISBN 978-0-12-802147-7.

5. Zhang, J.; Yan, J.; Huang, S.; Pan, G.; Chang, L.; Li, J.; Zhang, C.; Tang, H.; Chen, A.; Peng, D. Genetic Diversity and Population Structure of Cannabis Based on the Genome-Wide Development of Simple Sequence Repeat Markers. Front. Genet. 2020, 11, 958. [CrossRef] [PubMed]

6. Schultes, R.E.; Klein, W.M.; Plowman, T.; Lockwood, T.E. Cannabis: An example of taxonomic neglect. Bot. Mus. Leafl. Harv. Univ. 1974, 23, 337-367.

7. Hill, K.P.; Palastro, M.D.; Johnson, B.; Ditre, J.W. Cannabis and pain: A clinical review. Cannabis Cannabinoid Res. 2017, 2, 96-104. [CrossRef]

8. De Backer, B.; Maebe, K.; Verstraete, A.G.; Charlier, C. Evolution of the content of THC and other major cannabinoids in drug-type cannabis cuttings and seedlings during growth of plants. J. Forensic Sci. 2012, 57, 918-922. [CrossRef]

9. Brenneisen, R. Chemistry and analysis of phytocannabinoids and other Cannabis constituents. In Marijuana and the Cannabinoids; Humana Press: Totowa, NJ, USA, 2007; pp. 17-49. [CrossRef]

10. Mahlberg, P.G.; Kim, E.S. Accumulation of cannabinoids in glandular trichomes of Cannabis (Cannabaceae). J. Ind. Hemp 2004, 9 , 15-36. [CrossRef]

11. Bonini, S.A.; Premoli, M.; Tambaro, S.; Kurmar, A.; Maccarinelli, G.; Memo, M.; Mastinu, A. Cannabis sativa: A comprehensive ethnopharmacological review of a medicinal plant with a long history. J. Ethnopharmacol. 2018, 227, 300-315. [CrossRef]

12. Glivar, T.; Erzen, J.J.; Kreft, S.; Erzen, M.; Cerenak, A.; Ceh, B.; Benkovic, E.T. Cannabinoid content in industrial hemp (Cannabis sativa L.) varieties grown in Slovenia. Ind. Crop. Prod. 2020, 145, 112082. [CrossRef]

13. Herkenham, M.; Lynn, A.B.; Little, M.D.; Johnson, M.R.; Melvin, L.S.; De Costa Brian, R.; Rice, K.C. Cannabinoid receptor localization in brain. Proc. Natl. Acad. Sci. USA 1990, 87, 1932-1936. [CrossRef]

14. Bhattacharyya, S.; Crippa, J.A.; Martin-Santos, R.; Winton-Brown, T.; Fusar-Poli, P. Imaging the neural effects of cannabinoids: Current status and future opportunities for psychopharmacology. Curr. Pharm. Des. 2009, 15, 2603-2614. [CrossRef] 
15. D'Souza, D.C.; Perry, E.; MacDougall, L.; Ammerman, Y.; Cooper, T.; Braley, G.; Gueorguieva, R.; Krystal, J.H. The psychotomimetic effects of intravenous delta-9-tetrahydrocannabinol in healthy individuals: Implications for psychosis. Neuropsychopharmacology 2004, 29, 1558-1572. [CrossRef] [PubMed]

16. Crippa, J.A.; Zuardi, A.W.; Martin-Santos, R.; Bhattacharyya, S.; Atakan, Z.; McGuire, P.; Fusar-Poli, P. Cannabis and anxiety: A critical review of the evidence. Hum. Psychopharmacol. 2009, 24, 515-523. [CrossRef] [PubMed]

17. Zuardi, A.W.; Crippa, J.A.S.; Hallak, J.E.C.; Pinto, J.P.; Chagas, M.H.N.; Rodrigues, G.G.R.; Dursun, S.M.; Tumas, V. Cannabidiol for the treatment of psychosis in Parkinson's disease. J. Psychopharmacol. 2009, 23, 979-983. [CrossRef] [PubMed]

18. Hurd, Y.L. Leading the next CBD wave—Safety and efficacy. JAMA Psychiatry 2020, 77, 341-342. [CrossRef] [PubMed]

19. Taura, F.; Sirikantaramas, S.; Shoyama, Y.; Yoshikai, K.; Shoyama, Y.; Morimoto, S. Cannabidiolic-acid synthase, the chemotypedetermining enzyme in the fiber-type Cannabis sativa. FEBS Lett. 2007, 581, 2929-2934. [CrossRef] [PubMed]

20. Yang, Y.; Lewis, M.M.; Bello, A.M.; Wasilewski, E.; Clarke, H.A.; Kotra, L.P. Cannabis sativa (hemp) seeds, $\Delta 9$-tetrahydrocannabinol, and potential overdose. Cannabis Cannabinoid Res. 2017, 2, 274-281. [CrossRef]

21. Wang, M.; Wang, Y.; Avula, B.; Radwan, M.M.; Wanas, A.S.; van Antwerp, J.; Parcher, J.F.; ElSohly, M.A.; Khan, I.A. Decarboxylation study of acidic cannabinoids: A novel approach using ultra-high-performance supercritical fluid chromatography/photodiode array-mass spectrometry. Cannabis Cannabinoid Res. 2016, 1, 262-271. [CrossRef]

22. ICH Harmonised Tripartite Guideline. Validation of Analytical Procedures: Text and Methodology Q2(R1) 2005. Available online: https:/ / database.ich.org/sites/default/files/Q2\%28R1\%29\%20Guideline.pdf (accessed on 14 June 2021).

23. Welch, C.J.; Brkovic, T.; Schafer, W.; Gong, X. Performance to burn? Re-evaluating the choice of acetonitrile as the platform solvent for analytical HPLC. Green Chem. 2009, 11, 1232-1238. [CrossRef]

24. Singh, A.P.; Fathordoobady, F.; Guo, Y.; Singh, A.; Kitts, D.D. Antioxidants help favorably regulate the kinetics of lipid peroxidation, polyunsaturated fatty acids degradation and acidic cannabinoids decarboxylation in hempseed oil. Sci. Rep. 2020, 10, $1-12$.

25. Citti, C.; Pacchetti, B.; Vandelli, M.A.; Forni, F.; Cannazza, G. Analysis of cannabinoids in commercial hemp seed oil and decarboxylation kinetics studies of cannabidiolic acid (CBDA). J. Pharm. Biomed Anal. 2018, 149, 532-540. [CrossRef]

26. Pellati, F.; Brighenti, V.; Sperlea, J.; Marchetti, L.; Bertelli, D.; Benvenuti, S. New methods for the comprehensive analysis of bioactive compounds in Cannabis sativa L.(hemp). Molecules 2018, 23, 2639. [CrossRef] [PubMed]

27. Veress, T.; Szanto, J.I.; Leisztner, L. Determination of cannabinoid acids by high-performance liquid chromatography of their neutral derivatives formed by thermal decarboxylation: I. Study of the decarboxylation process in open reactors. J. Chromatogr. A 1990, 520, 339-347. [CrossRef] 